Max-Planck-Institut für demografische Forschung

Max Planck Institute for Demographic Research

Konrad-Zuse-Strasse 1 - D-18057 Rostock · GERMANY

Tel +49 (0) 3812081 - 0; Fax +49 (0) 3812081 - 202;

http://www.demogr.mpg.de

MPIDR WORKING PAPER WP 2006-038

NOVEMBER 2006

\title{
Intergenerational family ties and the diffusion of cohabitation in Italy
}

Paola Di Giulio (digiulio@demogr.mpg.de)

Alessandro Rosina

This working paper has been approved for release by: Gerda Ruth Neyer (neyer@ demogr.mpg.de)

Deputy Head of the Laboratory of Contemporary European Fertility and Family Dynamics.

(C) Copyright is held by the authors.

Working papers of the Max Planck Institute for Demographic Research receive only limited review. Views or opinions expressed in working papers are attributable to the authors and do not necessarily reflect those of the Institute. 


\title{
Intergenerational family ties and the diffusion of cohabitation in Italy
}

\author{
Paola Di Giulio \\ Max Planck Institute for Demographic Research, Rostock
}

Alessandro Rosina

Catholic University, Milan

\section{Introduction}

Cohabitation has been spreading in the industrial societies during the last thirty years, and this is one of the most striking aspects of general social changes that have taken place throughout these countries. The sudden gain in the popularity of cohabitation at the beginning of the 70s as an informal way of starting a union can be explained by several factors. Cultural elements, such as rising individualism and secularism, as well as economic aspects, such as changes brought by industrialization, changes in gender roles, and rising female labor-market participation, may have contributed to its increase (for a review, see Smock 2000). At the same time, the sexual revolution helped in removing the stigma surrounding premarital sex (Bumpass 1990). However, this change did not take place uniformly across Europe, one large exception being the Southern European countries. In the mid-90s, about one in three women aged 25-29 in Sweden and Denmark was cohabiting; this compares to more than one woman in four in France, about one woman in six in Germany and the Netherlands, and less than one woman in 20 in Italy (Kiernan 1999). Demographers disagree on whether the country differences in the prevalence of cohabitation are likely to disappear over time or whether they will persist, as there are fundamental structural and cultural differences between the societies (Bernhardt 2004).

Recent results from an analysis on the adoption of cohabitation among young Italian and German women (Nazio and Blossfeld 2003) seem to support researchers who do not see the differences disappearing over time, claiming that the diffusion of cohabitation among broad groups of the population in Italy is blocked. This is in contrast to the empirical evidence presented in other recent studies (Rosina 2002, 
Rosina and Billari 2003, Rosina et al. 2003, Barbagli 1997, Barbagli et al. 2003, Rosina and Micheli 2006). They show that cohabitation is recently spreading also in Italy and they argue that mechanisms related to the relationship between generations and specifically between Italian parents and their children - are at the basis of the adoption or rejection of new behaviors (Rosina and Fraboni 2004).

The purpose of this paper is to contribute to the current debate around the compatibility of cohabitation experiences with the Italian cultural context. We show that in Italy this relationship is not influenced solely by the characteristics of the adults have but also by some of their parents' characteristics. The strong ties between parents and children and a welfare state that provides very limited direct help to the youth are at the basis of the relatively scarce diffusion of non-marital cohabitation in Italy (Rosina and Fraboni 2004). Using an individual level diffusion model, we obtain results that are consistent with the crucial role that family ties play in the choice of cohabitation in place of (or before) marriage.

The paper is organized as follows: The next section presents the theoretical background and argues that the study of cohabitation in Italy needs to consider the role of family ties. To test our hypothesis, we use an approach proposed by Nazio and Blossfeld (2003), and slightly modify it in order to catch adequately the specificity of the Italian context, as will be highlighted in Section 3. Comments on the results of the analysis and a general discussion will close the paper.

\section{The role of family ties in the diffusion of cohabitation in Italy}

Not many studies have compared the Southern European situation with the rest of Europe or the rest of the Western industrialized world in terms of cohabitation. One of the most recent studies, a contribution by Nazio and Blossfeld (2003) on East and West Germany and Italy, concludes that the diffusion of cohabitation to broad groups of the Italian population seems to be blocked. This is due to the fact that " $[\ldots]$ cohabitation is indeed not an attractive choice in Italy" (Nazio and Blossfeld 2003: 77) and it seems to be "[...] confined to a small highly selective group of women [...]. As a rule these women are not religious, have left the education system and are employed, live mainly in the North and grew up in an urban context" (Nazio and Blossfeld 2003: 78). Moreover, the authors conclude that, similarly to East and West Germany, during the diffusion process the perceived experiences of peers (what they 
call the 'cumulative peer group adoption of cohabitation') exerts in general more influence on the decision to cohabit than the past adoption of this very behavior by earlier generations ('cumulative pre-cohort adoption'): "Peer groups should play a particularly influential role in the diffusion of cohabitation because in this case strongly held attitudes have to be changed, mainly at the beginning of the diffusion process" (Nazio and Blossfled 2003: 52).

The very interesting and methodologically promising analysis presented by Nazio and Blossfeld does not entirely catch and highlight some crucial Italian cultural context specificities related to the importance of family ties for the decision-making process of young adults on union formation. Their findings and conclusions can be cotrasted with the results of other studies (Rosina 2002, Rosina et al. 2003, Rosina and Billari 2003, Barbagli 1997, Barbagli et al. 2003), where it is stated that premarital cohabitation, after some decades of delay, started to spread also in Italy. The authors introduce the hypothesis that the cultural specificity of Italian family ties (Reher 1998, Dalla Zuanna and Micheli 2004) is more consistent with mechanisms related to the relationship between generations for the adoption of new behaviors than to the experience of peers.

More specifically, basing their analyses on a series of various data sources Rosina and Fraboni (2004) have argued that it is the very strong ties between Italian parents and their children that lay at the basis of the relatively scarce occurrence of non-marital cohabitation. The delay in diffusion would then not be due to the limited interest of the Italian youth towards this type of union, but to the "[...] convenience of the children in the Mediterranean area to avoid choices which are openly clashing with the values of parents [...]" (Rosina and Fraboni 2004: 162).

On the one side, it is indeed interesting to see that among the Italian youth of the 1980s there already was a favorable view of cohabitation. Many of them (two out of three) were ready to enter into cohabitation, but they felt that they live in a society that is not culturally open enough to accept this behavior (see e.g. Cavalli and De Lillo 1993). On the other side, although the children have positive inclinations towards cohabitation, they may refrain from cohabiting if their parents have a negative view of it, this in order to avoid financial or emotional sanctions (Axinn and Thornton 1993, Goldscheider and Goldscheider 1993, De Valk and Liefbroer 2004). The public nature of non-marital cohabitation suggests that children of parents who believe that cohabitation is not acceptable may not cohabit in order to avoid embarrassing their 
parents. The result may be that couples who want to enter informal cohabitation but whose parents disapprove of it may also prefer to marry rather than to cohabit (Axinn and Thornton 1993). This is especially true for Italian children. The need to receive parental support is indeed an important feature of the Southern European region. The welfare state in those countries is historically characterized by a "familialistic" approach, expressed in important transfers towards older generations and very limited direct help for the youth (Ferrera 1996, Esping-Andersen 1999). Given that the link between generations and the need to receive help is very important in the southern region, Southern European children are assumed to (and have to) take into account the attitudes of their parents towards their own potential choices.

For example, using data from a survey on young adults of ages 23-27 who still live in the parental home, Billari and Rosina (2005) show that the attitudes of parents concerning household formation choices have an important influence on their children when they decide to form (or not to form) a household, net of the attitudes and values of these children.

Moreover, based on the same data, Rosina and Micheli (2006) find empirical evidence that during the decision-making process of forming a household, Italian parents are very willing to provide generous support to their children if they conform to the parental expectations. Suffice it to mention support in buying a home as an example. The propensity to receive this help, however, diminishes significantly when children make choices that diverge from their parents' views. This is especially true when their young decide to start the first union with an informal cohabitation rather than marriage. In general, the strategic importance of parental support places young Italians at a disadvantage when they make choices that parents do not approve of, because this may lead to less generous parental help.

This kind of distinctive parental influence on children nowadays probably does not exist in Northern and Western Europe or it is unimportant to the youth in this region ${ }^{1}$. The welfare system there is more oriented towards helping young people in 'starting up'. At the same time (and for the same reason), people leave the parental home at very young ages. If this is true, then in the North-west European countries the very

\footnotetext{
${ }^{1}$ Most of the literature on cohabitation in those countries either ignore effect of the parents' characteristics or include them as a measure of the social background of the children. In relatively few papers the characteristic of the parents are used to assess the effect of their own preferences on the expected behavior of the children (for example de Singly 1986, Villeneuve-Gokalp 1991, Axinn and Thornton 1993, Liefbroer and de Jong Gierveld 1993, Schroeder 2005).
} 
generation that begins to open up to new behavior may engage in it straightaway. Taking the context of strong family ties, by contrast, the acceptance of innovative behavior among parents is a prerequisite of the process of diffusion of this behavior among their children (Rosina and Fraboni 2004). This effect may be caught better by the mechanisms linked to the influence the behavior of older cohorts has on the behavior of the younger generations.

More precisely, the literature has stressed that at least two different influences are active during the process of cohabitation diffusion: a) on the one side, the more the behavior spreads, the more the new generations will be aware of the new behavior as a possible option open to them before or as an alternative to marriage (knowledgeawareness mechanism). For example, the media increasingly presents information on the new habit, at least indirectly, on the costs and benefits of cohabitation, and its characteristics (Rogers 2003). The younger generations thus benefit from the ensuing greater social acceptability of the new behavior. This mechanism is linked to the cumulative experience of previous generations; b) on the other side, the simple knowledge of the existence of the new behavior is useful to form a personal opinion on it. Opinions do not necessarily translate into behaviors, however. In fact, it is also necessary that individuals can compare the cohabitation experiences made by people who have the same characteristics as them. Direct information about cohabitation experience will come from their peers by means of the so-called "direct social modeling mechanism"2 (Bandura 1977), under which we include the cumulative experience of cohabitation in peer groups.

Consistently with what just has been hypothesized, we expect that in Italy a positive attitude on cohabitation has largely preceded the diffusion of this behavior; in fact, as early as from the 1980s young adults have been showing a high acceptance of nonmarital cohabitation, and the vast majority declares to be ready to enter into it. But in difference to Nazio and Blossfeld (2003), we hypothesize that the adoption of cohabitation is influenced by mechanisms related to the behavior of earlier cohorts (cumulative experience of previous generations) more so than to the experience of cohabitation in the peer group.

\footnotetext{
2 The social learning theory of Bandura emphasizes the importance of observing and modeling the behaviors, attitudes, and emotional reactions of others. Bandura (1977:22) states: "Learning would be exceedingly laborious, not to mention hazardous, if people had to rely solely on the effects of their own actions to inform them what to do. Fortunately, most human behavior is learned observationally through modeling: from observing others one forms an idea of how new behaviors are performed, and on later occasions this coded information serves as a guide for action."
} 
To bring out the specificity of the Italian situation, in the empirical part we restrict our sample to women born in Central and Northern Italy. In general, Southern Italy and Northern and Central Italy show persisting historical differences in the models of family organization and household formation (Viazzo 2003). These differences are confirmed by the different demographic dynamics observed in the last decades in the three regions (Micheli 2000). To be more precise, in Southern Italy informal cohabitation in older as well as in younger generations remains at a marginal level and is almost exclusively due to the traditional phenomenon of the "fuitine" (Sabbadini 1991), which expresses the kidnapping of a young woman by her boyfriend in order to oblige her family to give consent to marriage. However, this is often carried out in complicity with the two families in order to avoid the expensive costs of a wedding party. It is usually followed by a frugal celebration of the marriage. This type of behavior cannot be considered a modern type of cohabitation, of which modern values and freedom of choice forms an integral part. In selecting only women born in Central and Northern Italy, it is possible to avoid that the determinants of the new and old type of cohabitation interlace and reciprocally obscure the effects.

Furthermore, forerunners of new behaviors usually belong to a population that enjoys a high cultural status (Goldscheider and Goldscheider 1999), and has enjoyed a high level of education, which in turn has a liberalizing effect on attitudes toward family and gender role behavior, for example (see, e.g., Trent and South 1992). According to our hypothesis, two separate and parallel kinds of open-mindedness are required to engage in a new behavior, like cohabitation: by the youth and by their parents. A central role in the diffusion process would then be played not only by the educational level of the youth, but, net of this, also by the educational level of the parents. Better educated parents are more liberal with regard to child rearing than less educated ones (van der Silk et al, 2002): open-minded parents are found to be more receptive to the influence of the more modern values of their children (Schoenpflug 1992, 2001, Pinquart and Silbereisen, 2004), they are more authoritative and less authoritarian ${ }^{3}$ in their parenting style (Rudy and Grusec 2001), they are more inclined to transmit modern gender role behaviors (Kulik 2005) and have more modern attitudes on

\footnotetext{
${ }^{3}$ Where "[...] authoritarian parenting [is] characterized by the imposition of an absolute set of standards, the valuing of obedience and respect for authority and the discouraging of give-and-take [...]. Authoritative parenting [is] characterized by firm control, high demands for maturity, and a willingness to reason and negotiate [...]" (Rudy and Grusec, 2001).
} 
premarital sex (Thornton and Camburn 1987). On the basis of the results obtained in previous analyses (Rosina and Billari 2003, Rosina and Fraboni 2004 - a diffusion approach was not used), we can expect that better educated fathers are more openminded, less dependent on context influence and social pressure, and represent less of an obstacle to the choice of their children. We consider the characteristics of fathers to be important because: a) fathers seem to care more so than mothers about their children's obedience to authority in terms of child-rearing values, and less-educated parents in particular are found to demand more conformity to their norms than the higher educated (Van der Slik et al. 2002); b) in the traditional gender system society, such as Italy until very recently, the husband was the "head" of the household in terms of the power-distribution in the family. The wife had some input in family decisionmaking, but she ultimately deferred this authority to his judgment. The mother provided childcare whereas the father served as authority figure to and disciplinarian of their children (Booth and Amato 1994, Schoenpflug 2001) ${ }^{4}$. This certainly is still applicable only to selected groups or to selected periods; it provides an approximate description of the way in which many families lived.

\section{Data and methods}

The data used stem from the "Seconda Indagine Nazionale sulla Fecondità"5 (the Italian Second Fertility Survey), carried out in Italy in 1995-96 (De Sandre 2000). The survey is part of the comparative round of the Family and Fertility Surveys and is representative at repartition (large region) level. Women and men aged 20-49 were interviewed, irrespective of their marital status, and retrospective information about family fertility and work career was collected. Compared to the international standard version of the database, the Italian version contains more variables of interest to the Italian context. Differently from Nazio and Blossfeld (2003), and because of the

\footnotetext{
4 The impact of the mother's level of education may play a role as soon as female participation in the educational system increases and the gender roles in the society and in the family become more egalitarian. The large educational reform of 1962, which made lower-secondary education (eight years of schooling) compulsory for everyone, could not yet have had an effect at the time the survey data we use was collected. For an analysis on the role of mothers on the union formation of their children in Italy see Schroeder (2005), and on the Turkish families in Germany see Schoenpflug (2001).

5 The difference between the data source we use and the one used by Blossfeld and Nazio (2003) is that in the national version of the database, all variables collected in the survey are available, not only those included in the comparative design, thus allowing for richer and more detailed analyses.
} 
reasons mentioned in the previous paragraphs, we select women ${ }^{6}$ resident in Northern and in Central Italy. For reasons of homogeneity, we restricted our sample to women born in Italy, who have an Italian nationality and belong to the 1954-1973 cohorts; this to avoid problems of selection and truncation.

Following the approach proposed by Nazio and Blossfeld (2003) and in order to model the diffusion of the innovation process, we apply an event-history analysis model that has special features. Rogers (2003) defines diffusion as a process in which innovation is transmitted to the members of a social system, over time and by means of various channels. The diffusion process approach permits to incorporate the probability of an individual to adopt innovative behavior as a function of the previous adoption of the same behavior from other individuals in the population (Strang and Tuma 1993). It therefore is especially relevant for the analysis of the experience of events, with the degree of acceptability changing in society according to the quota of the population that already experienced the event (Prinz 1995, Manting 1996). The inclusion of a diffusion approach in the event-history analysis permits to combine heterogeneity in individual level characteristics with the effect of the influence of individuals who have already adopted the new behavior ${ }^{7}$.

Very basically, an individual-level event-history analysis that includes a diffusion process can be formulated as:

$r_{n}(t)=\left[\exp \left(\alpha+\Sigma_{s \in S(t)} \beta\right)\right]$

\footnotetext{
${ }^{6}$ We limit our analysis to the behaviour of Italian women because young men's choice of the type of union is partially driven by factors other than those that drive women (Oppenheimer 2003) and because the small case number of the male sample makes it virtually impossible to perform the same analysis on men.

7 The very first diffusion models proposed consist of macro level models, where - exactly as in the study on the diffusion of an infectious disease - the probability of an already infected individual to infect another one is modelled. The first models strongly rely on the so called spatial homogeneity hypothesis (all individuals have the same probability of infecting someone or being infected, independent of where they live) and temporal homogeneity hypothesis (the infectiveness is the same at the beginning and at the end of the diffusion process) (Strang and Tuma 1993).

Both hypotheses make the mathematical treatment very simple, but in general not realistic. For this reason it has been proposed to use micro level models. This choice permits to take into account that a) that not all individuals have the same predisposition to adopt an innovative behaviour and b) that not all contacts between individuals have the same probability of being made and not all individuals are likely to be infected. This has been done combining the tradition of event- history analysis and the tradition of the diffusion process. The application of the diffusion process logic to event-history analysis techniques is not trivial and implies a careful consideration above all of why a certain behaviour should be shaped by the diffusion hypothesis and not, for example, by structural characteristics of the individual (for a discussion, see Braun and Engelhardt 2004, Palloni 2001).
} 
where $r_{n}(t)$ is the propensity that an individual belonging to the "non- adopters" set moves to adoption at time $t, \alpha$ stands for the effect of individual characteristics (that can modify susceptibility/willingness to adoption), $S(t)$ includes the set of previous adopters, and $\beta$ is the effect of the diffusion process on the individual probability of adopting the new behavior. In the equation, $\alpha$ includes all individual level variables that are assumed to influence susceptibility to the adoption of a certain type of union $\left(\alpha^{\prime} x(t)\right)$. The term $\beta$ includes two mechanisms catching the influence of the behavior of other people on the adoption of cohabitation; a) knowledge-awareness and b) direct social modeling (see the previous paragraph). In Nazio and Blossfeld (2003), the two mechanisms take the form of functions ${ }^{8}$ which at each point in time and for each age of the women respectively indicate a) the cumulative proportion that already adopted the new behavior (cohabitation as first union) in the older generations, labeled as PreCohort Adoption; b) the cumulative proportion of previous adopters belonging to their own generation, labeled as Peer-Group Adoption.

The event-history analysis model used is exponential, with competitive risks, and the time unit is the month. Women will be observed from age 15 (at which the risk to enter a union begins) until entrance into cohabitation or marriage (competitive risks approach). The censoring point is age 39 or the moment of the interview. Two time-

\footnotetext{
${ }^{8}$ As far as the diffusion of cohabitation is concerned, we can imagine that at the beginning of the diffusion only a small quota of the population (forerunners) experiences the new behaviour, and these individuals, for example, will develop new values. If the adoption is successful, as time passes by, each individual will be exposed to a growing quota of the population that experience the new behaviour. A young woman aged $\mathrm{x}$ will decide to marry or cohabit not only on the basis of personal preferences but also on the basis of two types of influences, labelled and computed as follows:

a) Pre-cohort, knowledge awareness is measured as the cumulative proportion that already adopted the new behaviour (cohabitation as first union) in the older generations, at each age:

$$
\mathrm{P}_{\mathrm{c}}=\left(\left(\Sigma_{\mathrm{i}<\mathrm{c}} \Sigma_{\mathrm{j}<\mathrm{t}} \mathrm{n}_{\mathrm{ij}}\right) / \mathrm{N}_{\mathrm{p}}(\mathrm{t})\right) * 100
$$

b) Peer group: the effect of the direct social modelling of peers is measured as the cumulative proportion of previous adopters belonging to their own generation at each age.

$$
\mathrm{P}_{\mathrm{g}}=\left(\left(\sum_{\mathrm{i}=\mathrm{c}} \Sigma_{\mathrm{j}<\mathrm{t}} \mathrm{m}_{\mathrm{ij}}\right) / \mathrm{N}_{\mathrm{c}}\right) * 100
$$

where:

$\mathrm{c}$ is the birth cohort

$t$ is the age of the woman in question

$\mathrm{m}_{\mathrm{ij}}$ is the number of adopters belonging to their own generation at age $t$

$\mathrm{N}_{\mathrm{c}}$ is the number of women belonging to their own generation

$\mathbf{n}_{\mathrm{ij}}$ is the number of previous adopters belonging to the older generations at age $t$

$\mathrm{N}_{\mathrm{p}}(t)$ is the number of women that belongs to the older generations at age $t$.
}

In difference to Nazio and Blossfeld, the terms peer group adoption, "Pg", and pre-cohort adoption, "Pc", have been included only as linear (and not polynomial) factors both because the diffusion process studied is still at the beginning and for a parsimonious criteria. In fact, as compared to the Nazio and Blossfeld model, ours has a lower number of observations because we excluded women resident in Southern Italy. For further details about the specification of the model, see Nazio e Blossfeld (2003). 
dependent variables are used to control the non-monotonic dependence from the time of the risk to enter union (Blossfeld and Huinink 1991): log (current age-15) and $\log (39$-current age).

Among the variables that measure the heterogeneity of individuals at the micro level ( $\alpha$ part of the model), there are both time constant and time dependent variables ${ }^{9}$ :

To be out of education: a dummy time-dependent variable that measures whether of not the woman in question has left the education system at a given age. From the normative point of view, to be out of education is an important prerequisite to start a marriage (Billari and Ongaro 1999). This may be much less so for the choice to start cohabiting. In fact, cohabitation is thought to be a less binding and more flexible living arrangement than is marriage, thus it may facilitate the reconciliation between education and affective life (Hoem 1986; Wu 2000).

Education level reached at a specific age, time-dependent, and measured by compulsory education, high school, and university. The level of education reached measures the accumulation of human capital, net of the current participation in the education system. The effect of the variable is two-fold: on the one side, cohabitation, being more gender-equal than marriage (Becker 1981), will be chosen by women who have a higher human capital and are more willing to challenge the traditional gender roles (Behrman 1997). On the other side, a higher education level can be seen as a vehicle of important cultural modernization, and thus we can expect that a greater number of modern women are more ready than traditional women to adopt a new living arrangement when this is perceived as favorable.

- Employment, a dummy variable that measures each time a woman has a job or not; it is a time-dependent proxy for economic independency.

- $\quad$ Religiosity, measured at interview. Women who are more religious will be less prone to choose cohabitation instead of marriage. Cautious interpretation should be made of the effect of variables measured at interview on previous behavior as religious behavior possibly impacts the choice of cohabitation and the choice of cohabiting in turn leads to a decline in religious attendance, given that this behavior is strongly disapproved by the Catholic Church.

9 Table A1 of the Appendix A displays the descriptive statistics of the main variables. 
Urbanization of the place of residence at age 15, in rural or small cities (up to 10.000 inhabitants), medium-sized cities (from 10.000 to 100.000) or large cities (more than 100.000 inhabitants); it is a proxy of the social control over individual choices, the latter which is thought to be less strong in large cities (Lesthaeghe and Neels 2002);

- $\quad$ Repartition of residence at interview: The social setting in Central and Northern Italy is more modern than in Southern Italy.

Education level of the father. This variable was not included in the Nazio and Blossfeld analysis (2003). It measures the extent of open-mindedness in the family context (see previous paragraph). A different classification of the highest education level reached has been used for fathers, given that participation in school has been growing in Italy only since the last decades. The basic education level for fathers thus corresponds to elementary school, the medium level to lower secondary school, and the highest level is 'high school at least'. Survey respondents were given the option to answer 'not indicated'. This category will prove to play an important role because if a respondent does not provide the information for the father this may imply that respondent and the father do not have a very close relationship.

\section{Results}

After having checked the information provided in the original data set, 3212 women born in 1954-1973 were selected, of which 208 have experienced cohabitation as first union. Of these, 1947 were resident in Central and Northern Italy at the age of 15 and 153 experienced first cohabitation.

First, the time-dependent variables (to be out of education, the level of education reached and the employment) and the time constant ones (repartition of residence at interview, urbanization of the residence at age 15 and religiosity) were included, together with the time dependent variables that control for the dependency on time of the baseline risk. Second, the model was restricted to women of Central and Northern Italy, and the education of the father was included.

Table 1 shows the results for the models run for all of Italy (1), Central and Northern Italy only (2) with (b) or without (a) the inclusion of the father's education level. The model for all of Italy without the inclusion of the education level of the father is 
substantially similar ${ }^{10}$ to the ones reported in Blossfeld Nazio (2003): to be out of education and to be employed significantly favor the start of a cohabitation ${ }^{11}$. To be religious, resident in Southern Italy and to live in small or medium-sized cities, characterized by traditional contexts, lower the risk of entering a cohabiting union, as expected. Both lower and higher educated women have a higher propensity to enter a cohabiting union. Although the authors interpret this finding as simply being the result of the continuous accumulating of human capital, it is possible that this effect interplays with the intrinsic characteristics of the diffusion process. In fact, at the beginning of the diffusion process traditional and modern behaviors co-exist. In Italy, we find the traditional type of cohabitation due to the economic difficulties connected with entering marriage (these are characteristic of the lower societal strata in the population) and those motivated by cultural modernization (new values and social change). As for the factors directly connected with the diffusion process, summarized in the variables peer-group adoption and pre-cohort adoption, the diffusion is above all driven by the first component. Thus the direct experience of peers would be a direct basis for the decision to cohabit, having a role that is more important than the generic information diffusion stimulated by the behavior of previous generations.

Comparing Models 1a (all of Italy) and 2a (only the Central and Northern Italy), it emerges that while for the first an important prerequisite to form a cohabitation is to be out of education, this is not important in Central and Northern regions. In fact, it seems that in the latter two regions cohabitations is experienced also as a flexible type of union during transition completion to adult stage, as happens in other European countries (there, cohabitation is a more wide-spread phenomenon). Moreover, although both variables on the diffusion process are positive, in Central and Northern Italy pre cohort adoption seems to have a significantly higher importance with respect to peer group adoption, as compared to the results for all of Italy.

\footnotetext{
10 See Di Giulio (2004).

11 In this model, to be out of education and employment are basic conditions that favor the start of cohabitation. Although cohabitation could be considered to be more compatible with investment in the education career than marriage, it is likely that variables that have a strong impact on starting a first union (whatever the type) play a large role. In particular, we need to take into account Italy's unfavorable housing market (Saraceno 1998); thus so not only will there be difficulties in finding a suitable flat but also the cost associated with it will sometimes be very high.
} 
Tab. 1 Estimation of covariate effects on the diffusion of cohabitation for women (Exponential model with time-constant and time-dependent covariates).

\begin{tabular}{|c|c|c|c|c|c|c|c|c|c|c|c|c|}
\hline & \multicolumn{6}{|c|}{ Italy } & \multicolumn{6}{|c|}{ Central and Northern Italy } \\
\hline & \multicolumn{3}{|c|}{ Model 1a } & \multicolumn{3}{|c|}{ Model 1b } & \multicolumn{3}{|c|}{ Model 2a } & \multicolumn{3}{|c|}{ Model 2b } \\
\hline & B & s.e. & & B & s.e. & & B & s.e. & & $\beta$ & s.e. & \\
\hline Intercept & -7.889 & 0,866 & * & $-7,912$ & 0,866 & $* *$ & $-9,266$ & 1,252 & $* *$ & $-9,335$ & 1,255 & $\begin{array}{l}* \\
*\end{array}$ \\
\hline Log(Age-15) & 0,221 & 0,120 & $*$ & 0,221 & 0,121 & $*$ & 0,503 & 0,204 & $* *$ & 0,505 & 0,204 & $\begin{array}{l}* \\
*\end{array}$ \\
\hline Log(39-Age) & $-0,003$ & 0,255 & & $-0,007$ & 0,254 & & 0,285 & 0,363 & & 0,269 & 0,364 & \\
\hline Out of education & 0,439 & 0,178 & $\begin{array}{l}* \\
*\end{array}$ & 0,474 & 0,184 & $* *$ & 0,151 & 0,203 & & 0,202 & 0,208 & \\
\hline $\begin{array}{l}\text { Education level } \\
\text { Compulsory (ref) }\end{array}$ & 0 & & & 0 & & & 0 & & & 0 & & \\
\hline High School & $-0,237$ & 0,160 & & $-0,258$ & 0,165 & & $-0,210$ & 0,187 & & $-0,235$ & 0,192 & \\
\hline University & 0,164 & 0,272 & & 0,068 & 0,290 & & 0,298 & 0,317 & & 0,211 & 0,333 & \\
\hline Employed & 0,697 & 0,169 & $\begin{array}{l}* \\
*\end{array}$ & 0,711 & 0,170 & $* *$ & 0,989 & 0,219 & $* *$ & 1,015 & 0,221 & $\begin{array}{l}* \\
*\end{array}$ \\
\hline Religiosity & $-1,054$ & 0,164 & $\begin{array}{l}* \\
*\end{array}$ & $-1,045$ & 0,164 & $* *$ & $-1,191$ & 0,173 & $* *$ & $-1,193$ & 0,173 & $\begin{array}{l}* \\
*\end{array}$ \\
\hline Rural/small city (ref) & 0 & & & 0 & & & 0 & & & 0 & & \\
\hline Middle-sized city & $-0,009$ & 0,181 & & $-0,028$ & 0,182 & & 0,087 & 0,217 & & 0,049 & 0,219 & \\
\hline Large city & 0,461 & 0,182 & * & 0,414 & 0,189 & $* *$ & 0,501 & 0,215 & $* *$ & 0,417 & 0,222 & $*$ \\
\hline North (ref) & 0 & & & 0 & & & 0 & & & 0 & & \\
\hline Centre & $-0,308$ & 0,202 & & $-0,316$ & 0,203 & $*$ & $-0,291$ & 0,204 & & $-0,277$ & 0,205 & \\
\hline South and Islands & $-0,298$ & 0,176 & $*$ & $-0,304$ & 0,176 & $*$ & & & & & & \\
\hline Pre-cohort Adoption & 0,064 & 0,054 & & 0,062 & 0,054 & & 0,090 & 0,052 & $*$ & 0,090 & 0,052 & $*$ \\
\hline Peer Group Adoption & 0,070 & 0,039 & $*$ & 0,071 & 0,039 & $*$ & 0,037 & 0,040 & & 0,033 & 0,040 & \\
\hline $\begin{array}{l}\text { Father's education level } \\
\text { Basic (ref) }\end{array}$ & & & & 0 & & & & & & 0 & & \\
\hline Lower Secondary School & & & & $-0,069$ & 0,186 & & & & & 0,139 & 0,204 & \\
\hline High School at least & & & & 0,254 & 0,211 & & & & & 0,317 & 0,241 & \\
\hline Not indicated & & & & 0,199 & 0,368 & & & & & 0,750 & 0,378 & * \\
\hline Events & \multicolumn{2}{|c|}{208} & & \multicolumn{3}{|c|}{208} & \multicolumn{3}{|c|}{153} & \multicolumn{2}{|c|}{153} & \\
\hline \multirow[t]{2}{*}{ Log-likelihood } & \multicolumn{2}{|c|}{$(-13668,3)$} & & \multicolumn{3}{|c|}{$(-13668,3)$} & \multicolumn{3}{|c|}{$(-8210,46)$} & \multicolumn{2}{|c|}{$(-8210,46)$} & \\
\hline & \multicolumn{3}{|c|}{$-13577,5$} & \multicolumn{3}{|c|}{$-13576,32$} & \multicolumn{3}{|c|}{$-8121,11$} & \multicolumn{2}{|c|}{$-8118,90$} & \\
\hline
\end{tabular}

In Models $1 b$ and $2 b$, both of which include the variable on the educational level of the father, we observe that the variable has no clear pattern as to Italy as a whole. The effect of a father's medium level of education is, in fact, negative as far as his daughter's cohabitation is concerned. Nevertheless, if we restrict our analysis to Central and Northern Italy (Model 2b), a clearer pattern emerges: daughters whose fathers have a lower education also have a lower propensity to experience cohabitation, net of the effect of all other variables. The propensity to form a 
cohabitation grows as the education level of the father grows (although the effect is not statistically significant), and women who declare that they do not know how high or low the education level of their father is have the strongest propensity. Here, the variable can be interpreted as a proxy for the closeness reached in the relationship between father and daughter: the absence of the father or a loose connection to him may weaken the normative control the father has over the daughter and significantly favor a freer choice on the type of union. This result is has been obtained by Wright and Young (1998) and Flouri and Buchanan (2001) in relation to gender related attitudes: children from father-headed one parent families have more traditional gender related attitudes than children from mother-headed one parent families.

An interesting insight into the process of experiencing first cohabitation is provided by an analysis of the complementary process, entry into first marriage. Comparing the effect the same variables have on the two events, we are able to emphasize their meaning. Given that it is not our goal to develop a specific diffusion model for marriage, we will compare two standard event-history models of analysis: In the first model, the time to first cohabitation will be studied; in the second we look at the time to first marriage. As with the previous models, the models will be exponential and have competitive risks. The variables on peer-group adoption and pre-cohort adoption will be substituted by dummy variables for the cohort of births. We compare the models in terms of time to first cohabitation and time to first marriage, use the categories Italy as a whole, only Central and Northern Italy, and include the father's level of education. The results are shown in Table 2.

As expected, employment and religiosity have an opposite relation to marriage and cohabitation, both in Italy as a whole and in the Central and Northern Italy only. The main result stems from the comparison of the effect of the father's level of education, however. Net to the characteristics of the women, the education level of the father has a negative effect on marriage and a positive impact on cohabitation; the effect is stronger in Central and Northern Italy than it is in Italy as a whole. Daughters of better educated men tend either to postpone marriage or to anticipate cohabitation (this result has a very low level of significance, though), supporting the statement that the educational level of the father acts as a cultural resource more so than an economic resource, and that the impact on the two phenomena is different. We also find that in Central and Northern Italy, missing information on the education level of the father 
has a positive impact both on the propensity to enter a cohabitation and to engage in marriage, but it has a large and significant impact only for cohabitation.

Tab. 2 Estimation of covariates' ${ }^{\text {a }}$ effects on first marriage and first cohabitation for women (Exponential model with time constant and time dependent covariates).

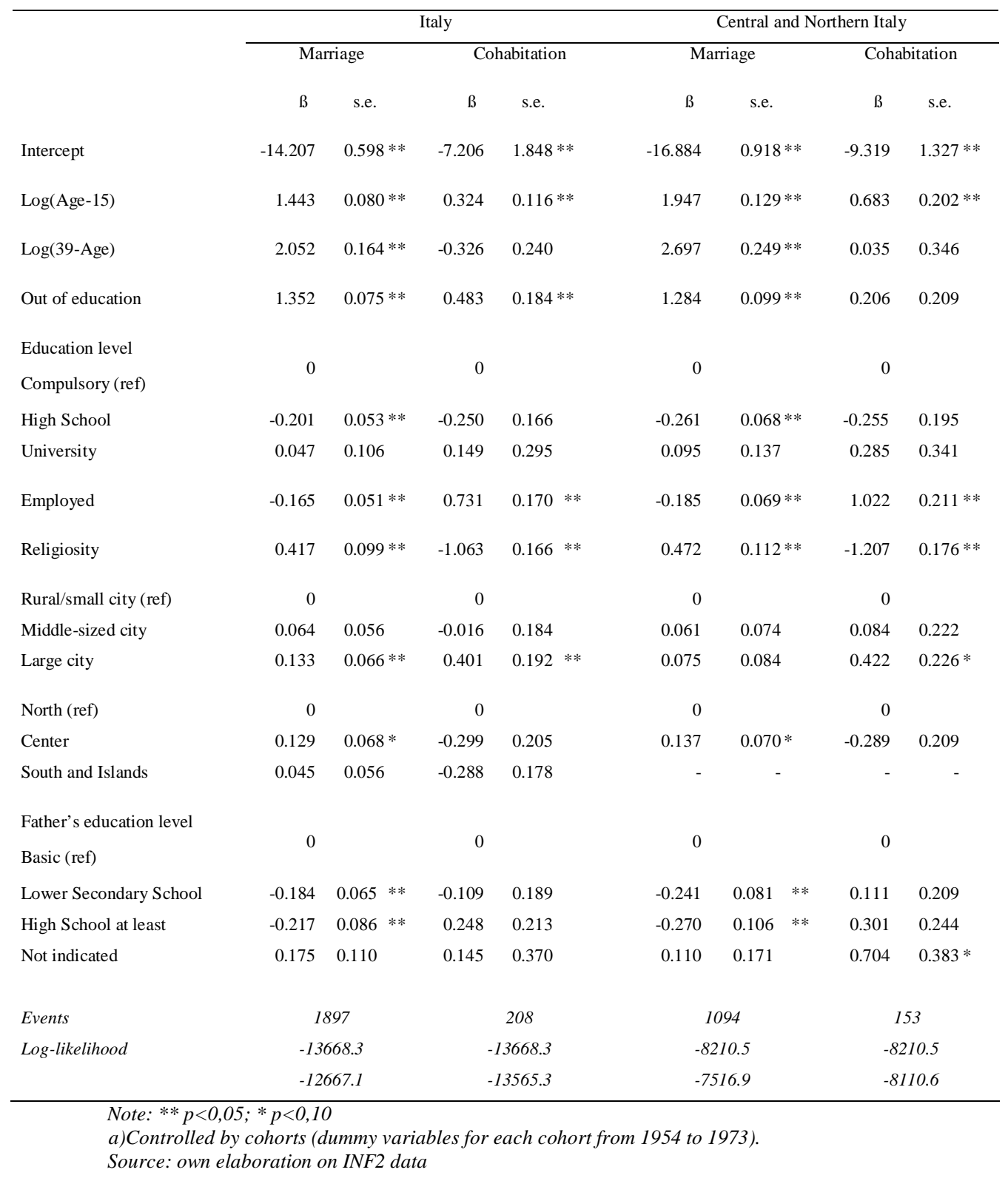




\section{Conclusions and discussion}

During the 1980s, non-marital cohabitation became a common living arrangement between the young people of North-West Europe. In Southern Europe, by contrast, it continues to constitute marginal behavior. This has led several authors to support the idea that cohabitation is not consistent with the Italian socio-cultural context and the debate continues to date (Bernhardt 2004). Recently, Nazio and Blossfled (2003) have analyzed the adoption of cohabitation among young Italian women, using an individual-level diffusion model. We believe that the analysis presented by them, interesting and stimulating as it is, does not highlight some important specificities of the Italian context. The authors conclude that the diffusion of cohabitation among young Italian women seem to be influenced more so by the behavior of peers than by the cumulative experience of previous cohorts, and that the diffusion of cohabitation in Italy seems to be blocked and confined to a selected group.

This in contrast to the results of other recent studies: they show that cohabitation, after some decades of delay, is spreading in Italy, too (Rosina 2002, Rosina et al. 2003, Rosina and Billari 2003) and that the cultural specificity of Italian family ties (Reher 1998, Dalla Zuanna and Micheli 2004) is more consistent with the hypothesis placing higher importance on the adoption of new behaviors to mechanisms related to the relationship between generations rather than to the experience of peers. Two key features characterize the specificity of the Southern European area: strong ties between parents and children and a welfare state that provides very limited direct help to the youth. Recently, Rosina and Fraboni (2004) have argued that it is exactly these features that are at the basis of the relatively scarce diffusion of non-marital cohabitation in Italy. As a consequence of the two key features, it is indeed strategically important for a young adult to receive parental support in the critical events of his/her life. The need to receive help places young Italians at a disadvantage when they make choices that their parents do not approve of, thus possibly rendering parental help less generous. Consistently with this hypothesis, the cumulative earlier cohort experience in Italy does not only contain knowledge-awareness as to the diffusion of cohabitation behavior between young people, but also catches the direct social modeling on the open-mindedness of parents. It plays a large role in the behavior of their children. This means that in Italy (and more generally in the strong 
family ties area), on difference to the Western and Northern European countries, the pre-cohort adoption tends to prevail on the peer group adoption. To test this hypothesis, we used the approach proposed by Nazio and Blossfled, introducing some important variations to adequately study the specificities of the Italian context. Diverse studies have highlighted that the household organization and family formation models present persistent differences between Northern and Southern Italy, with consequences on current behavior. In particular, in Southern Italy informal cohabitation remains at a marginal level, also in the youngest generations, and it is almost exclusively due to the traditional phenomenon of the "fuitine". Therefore, we restricted our sample to the women born in Central and Northern Italy. Furthermore, on the basis of our hypothesis, it is not only the educational level of the youth that has a crucial role in the diffusion of cohabitation, but also, net of this, the educational level of the parents. We expect that better educated fathers will be more open-minded, less dependent on context influence and social pressure, and less of an obstacle to their daughter's choice to cohabit.

Overall, the findings are consistent with this hypothesis. In the diffusion process of modern cohabitations in Italy, the influence of older generations is more important than the behavior of peers (same-age individuals). Furthermore, we found that the father's education level influence the possibility of the daughter to adopt innovative behaviors, controlling for many important factors. In particular, a high paternal education level has a negative effect on marriage and a positive one on cohabitation. Together with the outcome of previous analysis based on the same approach (Rosina and Fraboni 2004), these results imply that cohabitation may be more diffused in Italy than in the past. Higher education spreads wider in the young generations and the young people, who after all have in general more modern views on cohabitation, will soon become parents of their own. They will probably show no or less reservation as to the cohabitation experience of their children.

However, investigations into this direction require access to more recent data and a larger sample size than we have at our disposal. In fact, the data we use in our analysis were collected in the mid-90s, that is, at a time when the people that took advantage of the education reform in 1962 and were influenced by the new cultural environment following the 1968 movements, had children of adolescence age. Moreover, an extremely small number of people in the sample experienced first cohabitation and this makes all of our results relatively unstable. More consistent empirical evidence on 
the influence of family ties on the spread of informal cohabitation in Italy is needed, requiring surveys with a larger sample size and more detailed information, for example concerning attitudes of the youth, their parents (the mother as well as the father), and the kind of material and non-material support that parents give to their children during their transition to independent adulthood. Panel data would be especially useful to correctly estimate the causal link between the different impact of the attitudes of the individuals and of their parents on the behavior of young people.

Another aspect to consider is that the decision to form a union is naturally taken by two individuals. We should not ignore the fact that the partners may have different opinions and wishes about union formation, or that they may suffer from different kinds of social and familiar pressures regarding their future relationship as a couple. The couples we observe in the survey may have been formed as the result of a bargaining process, which is worth to investigate especially in a context of limited social acceptability of cohabitation.

Finally, the decision to form a union is not only influenced by the social and the cultural context, the parent's opinion or personal attitudes, but also by some other important contextual level characteristics, such as the availability of suitable and economic accommodation or the possibility to take advantage of policies aimed at facilitating youth transition to adulthood. Although extremely difficult to include in the analysis, these variables cannot be ignored if the aim is to provide a critical explanation for the delay of cohabitation diffusion in Italy.

\section{Acknowledgements}

We are grateful to Christoph Buehler for his very useful comments on earlier versions of this paper and to Susann Backer for the valuable editing of the language contained in this paper. 


\section{References}

Axinn W.G., Thornton A. (1993). "Mothers, Children and Cohabitation: the intergenerational effects of attitudes and behavior." American Sociological Review, 58, 2: 233-246.

Bandura A. (1977). Social Learning Theory. Englewood Cliffs, NJ: Prentice Hall.

Barbagli, M. (1997). Family and kinship in Italy. In: Gullestad M., and Segalen M., editors. Family and Kinship in Europe. London: Pinter: 33-48.

Barbagli M., Castiglioni M., Dalla Zuanna G. (2003). Fare famiglia in Italia. Un secolo di cambiamenti. Bologna: Il Mulino.

Becker G. S. (1981). A treatise on the family. Cambridge, Mass: Harvard University Press.

Behrman J. R. (1997). Intrahousehold distribution and the family. In Rosenweig M. R. and Stark O., editors. Handbook of Population and Family Economics. Vol I. Amsterdam: Elsevier Science:125-187.

Bernhardt E. (2004). "Cohabitation or marriage? Preferred living arrangements in Sweden", sdf-puzzle 04/2004 http://www.oif.ac.at/sdf/sdf04-04-bernhardt.pdf (date of access: September 2006).

Billari F. C., Ongaro F. (1999). Lasciare la famiglia d'origine: Quando e perché? In De Sandre A., Pinnelli A., Santini A., editors. Nuzialità e fecondità in trasformazione: percorsi e fattori del cambiamento. Bologna: Il Mulino: 327346.

Billari F., Rosina A. (2005). "Mamma' and the diffusion of cohabitation: the Italian case". Population Association of America, 2005 Annual Meeting, Philadelphia 2005, April.

Blossfeld H.P., Huinink J. (1991). "Human capital investments or norms of role transition? How women's schooling and career affects the process of family formation”. American Journal of Sociology, 97, 1,: 143-168.

Booth A., Amato P. R. (1994). "Parental Gender Role Nontraditionalism and Offspring Outcomes". Journal of Marriage and the Family, 56 , 4: 865-877.

Bumpass, LL. (1990). "What's happening to the family? Interaction between demographic and institutional change". Demography, 27, 4: 483-98.

Braun N., Engelhardt H. (2004). "Diffusion Processes and Event History Analysis". Vienna Yearbook of Population Research 2004.111-132. 
Cavalli, A. De Lillo. A. (1993). Giovani anni '90, Terzo rapporto IARD sulla condizione giovanile in Italia, Bologna: Il Mulino.

Dalla Zuanna G., Micheli G. (2004). Strong family, familism and lowest-low fertility. Dordrecht: Kluwer Academic Press.

De Sandre, P. (2000). "Patterns of fertility in Italy and factors of its decline". Genus, LVI, 1-2.

De Singly F. (1986). "L'union libre: un compromise”. Dialogue, 2.

De Valk H.A.G., Liefbroer A. C. (2004). "Invloed van ouders op relatievormingsvoorkeuren van Turkse, Marokkaanse en autochtone jongeren in Nederland". Migrantenstudies, 20, 3: 108-129.

Di Giulio P. (2004). Legami familiari forti e diffusione delle convivenze in Italia, Doctoral Thesis, Università La Sapienza, Roma.

Esping-Andersen, G. (1999). Social Foundations of Postindustrial Economies. New York: Oxford University Press.

Ferrera, M (1996). "The 'Southern Model' of Welfare in Social Europe". Journal of European Social Policy, 6, 1: 17-37.

Flouri E., Buchanan A. (2001). "What Predicts Traditional Attitudes to Marriage?" Children and Society, 15, $4: 263-271$.

Goldscheider, F., Goldscheider, C. (1993). "Whose Nest? A Two-Generational View of Leaving Home During the 1980s." Journal of Marriage and the Family, 55, 4: 851-862.

Goldscheider, F., Goldscheider, C. (1999). The changing transition to adulthood. Leaving and returning home. Thousand Oaks, CA: Sage.

Hoem J.M. (1986). "The impact of education on modern family union initiation." European Journal of Population, 2, 2: 113-133.

Kiernan K. (1999). "Cohabitation in Western Europe.” Population Trends, n. 96.

Lesthaeghe R., Neels K. (2002). "From the first to the second demographic transition: an interpretation of the spatial continuity of demographic innovation in France, Belgium and Switzerland." European Journal of Population, 18, 4: 325-360.

Liefbroer A., de Jong Gierveld J. (1993). "The Impact of Rational Considerations and Perceived Opinions on Young Adults' Union Formation Intentions.”. Journal of Family Issues, 14, 2: 213-235.

Manting D. (1996). "The changing meaning of cohabitation and marriage." European Sociological Review, 12, 1: pp. 53-65. 
Micheli G.A. (2000). "Kinship, family and social network: the anthropological embedment of fertility change in Southern Europe." Demographic Research, 3,13 .

Nazio T. and Blossfeld H.-P. (2003) “The Diffusion of Cohabitation among Young Women in West Germany, East Germany and Italy." European Journal of Population, 19, 1: 47-82.

Oppenheimer V. K. (2003). “Cohabiting and Marriage During Young Men's Career Development." Demography, 40, 1: 127-149.

Palloni A. (2001). Diffusion in Sociological Analysis. In Casterline J. B., editor. Diffusion Processes and Fertility Transition. Washington, D.C: National Academy Press.

Pinquart, M.,Silbereisen, R.K. (2004). "Transmission of values from adolescents to their parents: The role of value content and authoritative parenting." Adolescence, 39, 83-100.

Prinz C. (1995). Cohabiting, Married or Single. Avebury, England.

Reher D. S. (1998). "Family ties in Western Europe: persistent contrasts." Population and Development Review, 24, 2: 203-234.

Rogers E. M. (2003). Diffusion of Innovations. New York: Free Press

Rosina A. (2002). Le prime unioni alternative al matrimonio. In: Famiglie, mutamenti e politiche sociali Vol. I, Osservatorio Nazionale sulle famiglie e le politiche locali di sostegno alle responsabilità familiari, Bologna: il Mulino.

Rosina A., Billari F. (2003). Flessibilità all'entrata in unione: i precursori del cambiamento. In: Breschi M., Livi Bacci M., editors. La bassa fecondità in Italia: tra costrizioni economiche e cambio di valori. Udine: Forum.

Rosina A., Fraboni R. (2004). "Is marriage losing its centrality in Italy?" Demographic Research, 11: 149-172.

Rosina A., Fraboni R., Sabbadini L.L. (2003). "Diventare uomini e donne in Italia". In: Pinnelli A., Racioppi F., Retttaroli R., editors. Genere e demografia. Bologna: Il Mulino.

Rosina A., Micheli G. (2006). "Modelli familiari e negoziazione dei percorsi di transizione allo stato adulto". Proceedings from the Congress: Famiglie, nascite e politiche sociali, Accademia nazionale dei Lincei, Roma, 28 - 29 April 2005. 
Rudy D., Grusec J.E. (2001). "Correlates of authoritarian parenting in individualist and collectivist cultures and implications for understanding the transmission of values." Journal of Cross-Cultural Psychology, 32, 2: 202-212.

Sabbadini L.L. (1991). Le libere unioni. In: Menniti A. Le famiglie italiane negli anni '80. Monografie IRP, Roma.

Saraceno C. (1998). Mutamenti della famiglia e politiche sociali in Italia. Bologna: Il Mulino.

Schoenpflug, U. (2001). "Decision-Making Influence in the Family: A Comparison of Turkish Families in Germany and in Turkey." Journal of Comparative Family Studies, 32, 2: 219-230.

Schroeder C. (2005). "Cohabitation in Italy: do parents matter?" Rostock, MPIDR Working Paper WP-2005-030.

Smock P.J. (2000). "Cohabitation in the United States: An appraisal of Research Themes, Findings, and Implications.” Annual Review of Sociology, 26 :1-20.

Strang D., Tuma N. B. (1993). "Spatial and Temporal Heterogeneity in Diffusion." American Journal of Sociology, 29, 3: 614-639.

Trent K., South S. J. (1992) "Sociodemographic Status, Parental background, Chilhood Family Structure, and Attitudes toward Family Formation.” Journal of Marriage and the Family, 54, 2: 427-439.

Van der Slik F.W.P., De Graaf N.D., Gerris J.R.M. (2002). "Conformity to parental rules: Asimmetric Influences of Father's and Mother's Levels of Education", European Sociological Journal, 18, 4: 489-502.

Villeneuve-Gokalp C. (1991). "From Marriage to Informal Union: Recent Changes in the Behaviour of French Couples." Population an English Selection, 3: 81111.

Viazzo P.P. (2003), "What's so special about the Mediterranean? Thirty years of research on household and family in Italy." Continuity and Change, 18, 1: 111-137.

Wright DW, Young R (1998). "The effects of family structure and maternal employment on the development of gender-related attitudes among men and women.” Journal of Family Issues, 19, 3: 300-314.

Wu Z. (2000). Cohabitation. An Alternative Form of Family Living. Oxford: Oxford University Press. 


\section{APPENDIX A}

Tab. A1 Descriptive statistics of selected covariates.

\begin{tabular}{lll}
\hline & mean & st. dev \\
\hline Mean age at first cohabitation & & 4.4389 \\
Mean age at first marriage & 23.3923 & 3.7938 \\
Education level & 22.8380 & \\
Compulsory & & 0.4894 \\
High school & 0.3971 & 0.5001 \\
University & 0.4981 & 0.3063 \\
Never employed & 0.1047 & 0.4399 \\
Religiosity & & 0.2657 \\
Size of Municipality of residence at age 15 & 0.2621 & \\
Rural/small city & 0.9103 & 0.4575 \\
Middle-sized city & & 0.4949 \\
Large city & & 0.4461 \\
Region of residence & 0.2980 & \\
North & 0.4280 & 0.4975 \\
Centre & 0.2740 & 0.3912 \\
South and Islands & & 0.4806 \\
Father's education level & & 0.4925 \\
Basic & & 0.4127 \\
Lower Secondary School & & 0.3647 \\
High school at least & 0.4495 \\
\hline
\end{tabular}

Source: own elaboration on INF2 data 